\title{
Extra-articular manifestations of rheumatoid arthritis: risk factors for serious gastrointestinal events
}

\author{
Alexandre E Voskuyl, Mart A F J Van de Laar, Hein J Bernelot Moens, \\ Jan K Van der Korst
}

\begin{abstract}
Objectives-Serious upper gastrointestinal events are an important threat to patients with arthritis who are treated with non-steroidal anti-inflammatory drugs (NSAIDs). In this study risk factors for serious upper gastroinestinal events are identified in patients with possible or definite rheumatoid arthritis (RA).

Methods-A retrospective analysis of factors that might contribute to the risk of serious upper gastrointestinal events was performed in a cohort of 2315 consecutive patients with possible or definite RA. The relative influences of disease severity, drug treatment, particularly with corticosteroids, and history of peptic ulceration were analysed with a conditional logistic regression model for the 106 patients with serious upper gastrointestinal events and for an equal number of control patients who were matched for age, gender, number of criteria for $R A$, and disease duration.

Results-The incidence rate for serious upper gastrointestinal events was $4 \cdot 0 / 1000$ patients in each year. The study reconfirmed that age over 60 years, history of peptic ulceration, and use of corticosteroids are risk factors. The presence of extra-articular manifestations of RA was associated with a two to 11-fold increase in the risk for serious upper gastrointestinal events. This risk was independent of the use of corticosteroids. Conclusion-Disease severity, in particular the presence of extra-articular features, may be an important factor in the pathogenesis of upper gastrointestinal ulceration in patients with $R A$ who are treated with NSAIDs.
\end{abstract}

(Ann Rheum Dis 1993; 52: 771-775)

Gastric and duodenal ulcerations are major adverse effects of treatment with non-steroidal anti-inflammatory drugs (NSAIDs). Cross sectional endoscopic surveys in patients with arthritis show prevalences of $14-31 \%$ for superficial erosions of 'NSAID gastropathy'. ${ }^{2}$ Serious upper gastrointestinal events, such as symptomatic ulcers, bleeding, and perforation, occur less often. Analyses of cohort studies gave estimates of one to 20 serious upper gastrointestinal events for each 1000 NSAID users in one year. ${ }^{2-4}$ An incidence rate of $1.58 \%$ in each year for gastrointestinal related hospital admissions and $0 \cdot 19 \%$ for gastrointestinal related deaths was found in patients receiving NSAIDs for the treatment of rheumatoid arthritis (RA). ${ }^{3}$ Studies of mortality in RA show that the proportion of deaths due to gastrointestinal diseases is relatively high. ${ }^{4}$ Estimates of the relative risk for NSAID related serious upper gastrointestinal events and death vary widely. Risk ratios ranging from $1 \cdot 1$ to 29.5 have been reported from case-control and cohort studies. ${ }^{1256}$ Differences between these studies are related primarily to the definition of ulcer disease and the relative proportions of patients who are at particular risk. Many workers have urged that studies are conducted to identify such groups, in the hope of providing a rational basis for prophylaxis against serious upper gastrointestinal events.

Factors that convey additional risks for NSAID users are age above 60 years, concomitant use of corticosteroids, history of peptic ulceration or NSAID related gastrointestinal side effects, and, possibly, functional disability. ${ }^{2} 378$

Some, though not all, studies have suggested that the type of arthritis influences the risk of gastric or duodenal ulceration, RA being particularly suspect. ${ }^{369}$ In none of the relevant studies, however, is a distinction made between mild and severe cases of the disease. The purpose of this study was to investigate whether specific manifestations of RA are associated with an increased risk for serious upper gastrointestinal events.

Patients and methods

The outpatient department of the Jan van Breemen Institute provides rheumatological care for the Amsterdam region. Each year more than 10000 patients, including about 2500 new referrals, are seen by staff rheumatologists and residents. A database system was created to record and store detailed clinical and follow up information on all 2315 patients who had been clinically diagnosed as having possible,
Leiden, PO Box 9600,2300

RC Leiden,

The Netherlands.

Accepted for publication

27 July 1993 
probable, or definite RA and who were under observation between 1984 and 1988. These data were obtained by reviewing all patient charts according to an established protocol.

Cases of symptomatic gastric or duodenal ulcer, perforation, or bleeding were selected from this population. The criterion for inclusion was a serious upper gastrointestinal event occurring during disease follow up, with confirmation by endoscopy, radiology, or surgery. The controls, without a known serious upper gastrointestinal event, were matched for sex, age at onset of RA, number of American College of Rheumatology (ACR) criteria, and disease duration.

The following variables were selected from the available data for analysis: gender, age (at the time of the serious upper gastrointestinal events for case patients, average during follow up for control patients), ACR criteria for RA, ${ }^{10}$ and presence or absence of bony erosions, serositis, vasculitis, amyloidosis, and Sjögren's syndrome, the latter to be confirmed by biopsy or sialography. The second highest erythrocyte sedimentation rate (ESR) (Westergren) and past use of corticosteroids and disease modifying antirheumatic drugs (DMARDs) were also reviewed. The charts of all case patients and of an equal number of controls were subsequently reviewed in more detail. For each case, the NSAID used at the time of, or three months before, the first serious upper gastrointestinal event during disease follow up was recorded. For each matched control, we recorded the NSAID in use at the most nearly corresponding interval of time after disease onset. Other information retrieved from the charts were concurrent use of corticosteroids, mode of presentation of serious upper gastrointestinal event, and history of peptic ulceration before the onset of RA. To assess extra-articular and systemic manifestations of RA, we recorded all manifestations of extraarticular disease that occurred during follow up. These were skin abnormalities (ischaemic ulcers, digital ischaemia and gangrene, and palpable purpura), neuropathy (mononeuritis multiplex and sensory polyneuropathy, confirmed by electromyography), serositis (pleuritis, pericarditis), subcutaneous nodules, eye disease (episcleritis, retinal arteritis), cryoglobulinaemia, and nephropathy (erythrocyturia and cell casts). Any histological evidence of vasculitis was recorded.
STATISTICAL METHODS

For the analysis of the available data on the full study population, odds ratios with $95 \%$ confidence intervals were calculated using $2 \times 2$ tables. ${ }^{11}$ For selected variables a multiple logistic regression analysis was carried out. In the case-control study odds ratios with $95 \%$ confidence intervals were calculated using the Mantel-Haenszel test for linear association where appropriate. Subsequently, a conditional logistic regression analysis was performed.

\section{Results}

Table 1 gives the characteristics of the patient population. On the basis of retrospective data concerning only the initial workup in the outpatient clinic, $58 \%$ of the 2315 patients with a clinical diagnosis of RA fulfilled the ACR criteria for RA. With the inclusion of follow up information on nodules, hand radiographs, and rheumatoid factors, this increased to $67 \%$. A serious upper gastrointestinal event was identified in $106(4.6 \%)$ patients with a clinical diagnosis of $\mathrm{RA}$; of these, $86(81 \%)$ fulfilled the ACR criteria for RA. ${ }^{10}$ Given a follow up duration of 26426 person years, this yields an estimated incidence rate of 4.0 serious upper gastrointestinal event per 1000 patients per year. Of these 106 patients, 48 had had duodenal ulceration and 47 gastric ulceration. In 11 cases, the information on localisation was inadequate. Upper gastrointestinal symptoms were the presenting feature in $72(68 \%)$ patients, bleeding in 24 $(23 \%)$, and acute abdominal pain in $12(11 \%)$. Diagnoses were established by radiology in 45 $(42 \%)$ cases and by endoscopy in 47 (44\%). Laparotomy was required in 17 patients, in four of whom a perforated ulcer was found. The deaths of five patients $(5 \%)$ were related to a serious upper gastrointestinal event, which corresponds to the death rate in other studies. ${ }^{4}$

Table 2 gives the odds ratio for selected variables for serious upper gastrointestinal events based on the data from the full study population. Significant differences were found for age (over 70 years); the presence of the ACR criteria for arthritis in more than three joints, symmetrical arthritis, and rheumatoid factor; the presence of more than four ACR criteria; the presence of bony erosions; the presence of amyloidosis; the presence of Characteristics of the full popu

\begin{tabular}{llll}
\hline & $\begin{array}{l}\text { Full study population } \\
(n=2315)\end{array}$ & $\begin{array}{l}\text { Case patients } \\
(n=106)\end{array}$ & $\begin{array}{l}\text { Matched control } \\
\text { patients }(n=106)\end{array}$ \\
\hline No (\%) female & $1560(67)$ & $68(64)$ & $68(64)$ \\
Mean (range) [SD] age at onset of RA (years) & $49 \cdot 9(17$ to 89$)$ & $51 \cdot 7[14 \cdot 5] \cdot$ & $50 \cdot 7[14 \cdot 8]$ \\
Mean (range) [SD] disease duration (years) & $11 \cdot 6(0$ to 68$)$ & $15 \cdot 9[11 \cdot 5]$ & $13 \cdot 4[10 \cdot 6]$ \\
ACR criteria at start of RA (No (\%) of patients) & $1125(49)$ & $51(48)$ & $53(50)$ \\
Morning stiffness & $1616(70)$ & $89(84)$ & $81(75)$ \\
Arthritis ₹three joints & $1831(79)$ & $90(85)$ & $92(87)$ \\
Arthritis of hand joints & $1671(72)$ & $86(81)$ & $89(84)$ \\
Symmetrical arthritis & $227(10)$ & $15(14)$ & $21(20)$ \\
Subcutaneous nodules & $820(35)$ & $46(43)$ & $42(40)$ \\
Radiological erosion of hand & $894(39)$ & $54(51)$ & $53(50)$ \\
Rheumatoid factors & $1343(58)$ & $72(68)$ & $72(68)$ \\
At least four ACR criteria for RA (No (\%) of patients) & $1551(67)$ & $86(81)$ & $85(80)$ \\
$\quad$ At initial workup & & & \\
During follow up & & & \\
\hline
\end{tabular}


Table 2 Frequencies of variables of potential interest and odds ratios for a serious upper gastrointestinal event (SUGE) in patients with a clinical diagnosis of rheumatoid arthritis $(R A)$

\begin{tabular}{|c|c|c|c|}
\hline & $\begin{array}{l}\text { No (\%) patients } \\
\text { with } R A \text { without an } \\
\text { SUGE (= 2209) }\end{array}$ & $\begin{array}{l}\text { No }(\%) \text { patients } \\
\text { with } R A \text { with an } \\
\text { SUGE }(n=106)\end{array}$ & $\begin{array}{l}\text { Odds ratio } \\
\text { (95\% confidence } \\
\text { interval) }\end{array}$ \\
\hline $\begin{array}{l}\text { Female } \\
\text { Age (years) }\end{array}$ & $1560(71)$ & $68(64)$ & $0.74(0.49$ to 1.11$)$ \\
\hline $\begin{array}{l}<40 \\
40-50 \\
50-60 \\
60-70 \\
>70\end{array}$ & $\begin{array}{l}327(15) \\
375(17) \\
571(26) \\
558(25) \\
378(17)\end{array}$ & $\begin{array}{c}5(5) \\
12(11) \\
27(25) \\
33(31) \\
29(27)\end{array}$ & $\begin{array}{l}0.29(0.13 \text { to } 0.74) \\
0.63(0.35 \text { to } 1.18) \\
0.98(0.64 \text { to } 1.55) \\
1.34(0.89 \text { to } 2.05) \\
1.83(1.19 \text { to } 2.85)\end{array}$ \\
\hline $\begin{array}{l}\text { ACR criteriat } \\
\text { Morning stiffness } \\
\text { Arthritis ₹three joints } \\
\text { Arthritis of hand joints } \\
\text { Symmetrical arthritis } \\
\text { Subcutaneous nodules } \\
\text { Radiological erosion of hand } \\
\text { Rheumatoid factors }\end{array}$ & $\begin{array}{r}1074(49) \\
1527(69) \\
1741(79) \\
1585(72) \\
212(10) \\
774(35) \\
840(38)\end{array}$ & $\begin{array}{l}51(48) \\
89(84) \\
90(85) \\
86(81) \\
15(14) \\
46(43) \\
54(51)\end{array}$ & $\begin{array}{l}0.98(0.67 \text { to } 1.45) \\
2.33(1.36 \text { to } 3.84) \\
1.50(0.86 \text { to } 2.52) \\
1.69(1.02 \text { to } 2.71) \\
1.56(0.91 \text { to } 2.49) \\
0.96(1.41 \text { to } 2.11) \\
1.69(1.15 \text { to } 2.49)\end{array}$ \\
\hline $\begin{array}{l}\text { Number of ACR criteria } \\
\text { At least four at first visit } \\
\text { At least four at follow up }\end{array}$ & $\begin{array}{l}1271(58) \\
1465(66)\end{array}$ & $\begin{array}{l}72(68) \\
86(81)\end{array}$ & $\begin{array}{l}1.57(1.03 \text { to } 2.36) \\
2.21(1.33 \text { to } 3.53)\end{array}$ \\
\hline $\begin{array}{l}\text { ESR } \geqslant 60 \mathrm{~mm} / \mathrm{h} \\
\text { Joint erosion } \neq \\
\text { Amyloidosis } \\
\text { Extra-articular manifestations } \\
\text { Serositis } \\
\text { Vasculitis } \\
\text { Siögren's syndrome } \\
\text { Corticosteroid use§ }\end{array}$ & $\begin{array}{c}862(39) \\
1587(72) \\
12(1) \\
514(23) \\
46(2) \\
55(2) \\
275(12) \\
413(19)\end{array}$ & $\begin{array}{c}73(69) \\
92(87) \\
4(4) \\
39(37) \\
3(3) \\
7(7) \\
24(23) \\
38(36)\end{array}$ & $\begin{array}{l}3.46(2.26 \text { to } 5.20) \\
2.56(1.43 \text { to } 4.39) \\
7.29(2.58 \text { to } 23.08) \\
1.92(1.29 \text { to } 2.89) \\
1.41(0.52 \text { to } 4.75) \\
2.80(1.33 \text { to } 6.44) \\
2.06(1.31 \text { to } 3.33) \\
2.43(1.62 \text { to } 3.68)\end{array}$ \\
\hline
\end{tabular}

ACR $=$ American College of Rheumatology.

^Age at first SUGE after onset of RA for case patients; average age during follow up for others. tNumber of patients with the individual ACR criteria ${ }^{10}$ at first workup in the outpatient clinic. $\ddagger$ Bony erosions in any joint at last follow up examination.

¿Corticosteroid use at any time of disease follow up.

Table 3 Odds ratios for separate categories indicating severity of rheumatoid arthritis $(R A)$ calculated with logistic regression analysis

\begin{tabular}{lll}
\hline Category & $\begin{array}{l}\text { Odds ratio for all } \\
\text { patients with a } \\
\text { clinical diagnosis of } R A\end{array}$ & $\begin{array}{l}\text { Adjusted odds ratio for } \\
\text { patients with at least four } A C R \\
\text { criteria for } R A \text { at last follow up }\end{array}$ \\
\hline Corticosteroid use & $1.99(1.30$ to 3.06$)$ & $2.02(1.37$ to 3.23$)$ \\
Arthritis in at least three joints & $1.89(1.09$ to 3.27$)$ & $1.36(0.67$ to 2.78$)$ \\
Bony erosions on any radiograph & $2.04(1.13$ to 3.69$)$ & $1.62(0.78$ to 3.35$)$ \\
Extra-articular manifestations & $1.57(0.97$ to 2.57$)$ & $1.60(0.95$ to 2.69$)$ \\
\hline
\end{tabular}

ACR = American College of Rheumatology.

${ }^{\star}$ Rheumatoid nodules, serositis, vasculitis, or Sjögren's syndrome.

Sjögren's syndrome; and the use of corticosteroids at any time during follow up. An increased risk for serious upper gastrointestinal events was also found for patients treated at any time during follow up with auro- thioglucose, D-penicillamine, azathioprine, methotrexate, or cyclophosphamide, but not for those treated with antimalarial drugs, gold by mouth, or sulphasalazine (data not shown). Patients with a high ESR throughout the course of their disease were also at higher risk for a serious upper gastrointestinal event. Gender was not found to be a risk factor.

There are clearly interdependencies among the variables that were associated with a serious upper gastrointestinal event. To assess the extent of their influence, three categories of clinical relevance were distinguished according to severity of joint disease (arthritis of more than three joints, bony erosions), presence of extra-articular manifestations (rheumatoid nodules, vasculitis, serositis, Sjögren's syndrome), and use of corticosteroids. With logistic regression analysis adjusted odds ratios were calculated for these categories (table 3). Each factor appeared to contribute to the risk for a serious upper gastrointestinal event, though not significantly for extra-articular manifestations. If patients fulfilling the ACR criteria for RA are considered separately, then only corticosteroid use (at any time during follow up) is a risk factor for a serious upper gastrointestinal event (table 3 ).

\section{MATCHED CASE-CONTROL STUDY}

The average disease duration was 15.9 years in the serious upper gastrointestinal event group and 13.5 years in control group. Matching was otherwise satisfactory (table 1). The number of patients using NSAIDs in the period preceding a serious upper gastrointestinal event was nearly the same as that of control patients using NSAIDs during the corresponding period: 97 and 93 respectively. Of these, indomethacin (45 cases; 27 controls) and butazolidin (nine cases; 10 controls) were used by a greater percentage of cases than controls. There was no difference between the two groups with respect to other NSAIDs. The use of corticosteroids and history of peptic ulcers were also found more often among cases (table 4).

Table 4 (Adjusted) Odds ratios for serious upper gastrointestinal events in case-control study calculated with conditional logistic regression analysis

\begin{tabular}{|c|c|c|c|c|c|c|}
\hline & $\begin{array}{l}\text { Case } \\
\text { patients } \\
(n=106)\end{array}$ & $\begin{array}{l}\text { Matched } \\
\text { control } \\
\text { patients } \\
(n=106)\end{array}$ & Odds ratio* & $\begin{array}{l}\text { Adjusted odds ratio } \\
\text { for history of peptic } \\
\text { disease }\end{array}$ & $\begin{array}{l}\text { Adjusted odds ratio } \\
\text { for history of peptic } \\
\text { disease and } \\
\text { corticosteroid use } \\
\text { or presence of } \\
\text { extra-articular } \\
\text { manifestations }\end{array}$ & $\begin{array}{l}\text { Adjusted odds ratio for history } \\
\text { of peptic disease and } \\
\text { corticosteroid use or presence of } \\
\text { extra-articular manifestations } \\
\text { in matched patients with at } \\
\text { least four ACR criteria for } R A \\
(n=86)\end{array}$ \\
\hline $\begin{array}{l}\text { History of peptic disease before } \\
\text { onset RA }\end{array}$ & 12 & 2 & $11.00(1.39$ to 88.05$)$ & & & \\
\hline Corticosteroid use $\nmid$ & 23 & 14 & $1.90(0.86$ to $4 \cdot 15)$ & $1.56(0.69$ to 3.50$)$ & $\begin{array}{l}1.48(0.59 \text { to } 3.73) \| \\
1.33(0.49 \text { to } 3.69) \|\end{array}$ & $\begin{array}{l}1.25(0.47 \text { to } 3.33) \\
1.17(0.39 \text { to } 3.48)\end{array}$ \\
\hline \multicolumn{7}{|c|}{ Number of extra-articular manifestations $\ddagger$} \\
\hline None & & 75 & & & & \\
\hline $\begin{array}{l}\text { One } \\
\text { Two }\end{array}$ & 24 & 27 & $2 \cdot 21(1.43$ to $3 \cdot 42)$ & $2 \cdot 15(1.38$ to $3 \cdot 15)$ & $2 \cdot 13(1 \cdot 37$ to $3 \cdot 31)$ & $1.99(1.29$ to 3.09$)$ \\
\hline Three of four & $\begin{array}{l}12 \\
14\end{array}$ & 1 & & & & \\
\hline $\begin{array}{l}\text { Presence of extra-articular } \\
\text { manifestations other than } \\
\text { nodules or cryoglobulinaemias }\end{array}$ & 37 & 5 & $12.00(3.60$ to 39.92$)$ & $11.41(3.42$ to 38.05$)$ & $11.20(3.35$ to 37.41$)$ & $9.31(2.83$ to 30.66$)$ \\
\hline
\end{tabular}

ACR = American College of Rheumatology; RA = rheumatoid arthritis.

*(Adjusted) Odds ratios with $95 \%$ confidence interval.

tCorticosteroid use at any time during disease follow up.

$¥$ (Adjusted) Odds ratios have a linear progression for the number of extra-articular manifestations.

§Vasculitis proved by biopsy, neuropathy, nephropathy, skin ulceration, serositis, or eye disease.

TOdds ratio for the number of extra-articular manifestations.

||Odds ratio for the presence of extra-articular manifestations other than nodules or cryoglobulinaemia. 
Table 5 Extra-articular manifestations in case and control patients. Values are number of patients

\begin{tabular}{lcc}
\hline & $\begin{array}{l}\text { Case } \\
\text { patients }\end{array}$ & $\begin{array}{l}\text { Control } \\
\text { patients }\end{array}$ \\
\hline Vasculitis proved by biopsy & 11 & 2 \\
Neuropathy & 7 & 1 \\
Nephropathy & 14 & 1 \\
Skin ulceration & 20 & 4 \\
Serositis & 3 & 0 \\
Eye disease & 2 & 0 \\
Rheumatoid nodules & 31 & 28 \\
Cryoglobulinaemia & 3 & 0 \\
\hline
\end{tabular}

Extra-articular and systemic manifestations of RA were more often present among cases than among controls (tables 4 and 5). Vasculitis was reported from 11 biopsy samples in an equal number of cases. This included eight skin biopsy samples. Other specimens were taken from the rectum, jejunum, and kidney. Skin biopsy samples showed vasculitis in two control patients.

The odds ratio for a serious upper gastrointestinal event, as calculated with a conditional logistic regression analysis, was higher when multiple extra-articular disease features were present (table 4). In the presence of extra-articular disease manifestations other than rheumatoid nodules and cryoglobulinaemia the odds ratio was $11 \cdot 2$, independent of a history of peptic disease and corticosteroid use. In matched patients fulfilling the ACR criteria for RA, the adjusted odds ratio was $9 \cdot 3$.

\section{Discussion}

Non-steroidal anti-inflammatory drug gastropathy is usually asymptomatic and self limiting (gastric adaptation has been suggested), and there is no conclusive evidence that the lesions bleed or progress to gastric ulceration. ${ }^{15612}$ Serious gastrointestinal events are much more important from a clinical point of view. Peptic ulceration, which is sometimes masked by the analgesic effect of NSAIDs, can lead to haemorrhage or perforation, which can result in sudden death. The incidence rate found in this retrospective study-four serious upper gastrointestinal events in 1000 patients with $\mathrm{RA}$ in a year-is comparable with the rates given in previous studies. ${ }^{13}$

Our results confirm that several previously reported factors are associated with a higher risk for a serious upper gastrointestinal event: age above 60 years, history of peptic ulceration, and use of corticosteroids. Fries et al suggested that disability of functional class two or higher also constitutes a risk factor for a serious upper gastrointestinal event in patients with RA. ${ }^{3}$ The question then arises as to whether ulceration is caused by RA or by its treatment.

It has often been suggested that $R A$ is associated with an increased risk for peptic ulceration. ${ }^{13613}$ This was left unconfirmed in a study by Malone et al. ${ }^{9}$ The present study population is not suitable for investigating the risk associated with $\mathrm{RA}$ itself, as a clinical diagnosis of RA was the primary inclusion criterion. The risk for a serious upper gastrointestinal event among patients with possible RA was half that among patients who fulfilled the ACR criteria (table 2), however.

The purpose of this study was to investigate the influence of specific manifestations of RA on serious upper gastrointestinal events. The context for this is the widely reported, but controversial, association between peptic ulceration and the concurrent use of corticosteroids and NSAIDs. ${ }^{8}{ }^{14-16}$ This combination of drugs is probably used more often in the treatment of RA than in that of any other disease. It is not known whether the risk associated with steroids arises from drug toxicity alone or from toxicity in combination with the severity of the underlying disease. The usual reason for starting corticosteroid treatment is unresponsiveness to NSAIDs and DMARDs, or the appearance of extra-articular manifestations. The increased frequency of serious upper gastrointestinal events could, therefore, be a direct consequence of widespread inflammatory activity. It is also possible that peptic ulceration is itself an extraarticular manifestation of RA.

In the initial evaluation of our patient data we observed associations of serious upper gastrointestinal events with factors related to severity of joint disease, with the presence of extra-articular manifestations, and also with treatment with certain DMARDs or corticosteroids (table 2). These associations were also present when the data were stratified for these variables, though not statistically significant for extra-articular manifestations (defined as vasculitis, serositis, Sjögren's syndrome, and rheumatoid nodules) (table 3). If only patients fulfilling the ACR criteria for RA were considered, then corticosteroid use (at any time during follow up) appeared to be a risk factor for serious upper gastrointestinal events (table 3).

To avoid bias by the most obvious confounders we matched control patients with patients with a serious upper gastrointestinal event for age, sex, number of ACR criteria, and disease duration. The shorter average disease duration among the control patients might have influenced our results. It seems improbable that this difference could be relevant for the occurrence of extra-articular disease manifestations, however, as the disease duration was longer than 10 years in both groups.

Our results indicate a two to 11-fold increased risk for a serious upper gastrointestinal event in patients with RA with extraarticular disease manifestations. The strong relation between a serious upper gastrointestinal event and extra-articular manifestations persisted in subgroups with specific combinations of extra-articular manifestations and increased with the number of different features present. The absence of an association between nodules and a serious upper gastrointestinal event is a consequence of the matching procedure: case and control patients were matched for ACR criteria, one of which is the presence of nodules (table 5).

Does tissue damage caused by RA contribute to upper gastrointestinal ulceration? 
We observed the highest risk in a group of 37 cases in whom extra-articular manifestations other than nodules or cryoglobulinaemia occurred. We think it improbable that this risk is attributable to the use of corticosteroids, which had been prescribed because of the greater severity of the disease. Corticosteroids were used by only 12 of these 37 patients $(32 \%)$ at the times of the serious upper gastrointestinal events and by two of five matched control patients $(40 \%)$. It cannot be excluded, however, that the case patients were using higher doses of NSAIDs. Data on the doses used at the times of ulceration could, unfortunately, not be assessed reliably from the patients' notes. Smoking rate, another supposed risk factor for gastrointestinal ulcers, also could not reliably be obtained from the charts.

The integrity of the gastrointestinal mucosa depends on the balance between defensive and offensive mechanisms. The results of this study suggest that the severity of RA is an independent factor in ulcer formation. Two hypotheses can be considered to explain this. Firstly, increased levels of proinflammatory substances-for example, cytokines or toxic products-may accelerate ulcer formation. ${ }^{17} 18$ Secondly, the impairment of mucosal blood flow may hinder defensive mechanisms. ${ }^{19}$ Indomethacin and aspirin rapidly induce microvascular damage to venules and reduce mucosal blood flow. ${ }^{19}{ }^{20}$ Leucocyte adhesion is an important additional factor in the subsequent process leading to mucosal damage. $^{2122}$ Thus conditions that alter local blood flow may be risk factors for gastric mucosal damage. Extra-articular manifestations of RA are commonly accompanied by inflammation of the vascular wall.

Our data suggest that severe RA, in particular the presence of extra-articular or systemic manifestations, is a significant risk factor for serious upper gastrointestinal events and that the risk is independent of the use of corticosteroids. The implication is that patients with RA with extra-articular disease manifestations need careful monitoring and, perhaps, prophylaxis. The effectiveness of prophylaxis in this high risk group has yet to be established.
We are grateful to $\mathrm{A} \mathrm{H}$ Zwinderman, $\mathrm{PhD}$, department of medical statistics, University of Leiden for statistical support.

1 Soll A H, Weinstein W M, Kurata J, McCarthy D. Nonsteroidal anti-inflammatory drugs and peptic ulcer disease. Ann Intern Med 1991; 114: 307-19.

2 Gabriel S E, Jaakkimainen L, Bombardier C. Risk for serious gastrointestinal complications related to use of nonsteroidal anti-inflammatory drugs. Ann Intern Med nonsteroidal anti-in

3 Fries J F, Williams C A, Bloch D A, Michel B A Nonsteroidal antiinflammatory D A, Michel B A. gastropathy: incidence and risk factor models. $\mathrm{Am} \mathcal{f} \mathrm{Med}$ 1991; 91: 213-22.

4 Pincus T, Griffin $M$. Gastro-intestinal disease associated with nonsteroidal anti-inflammatory drugs: new insights from observational studies and functional status questionnaires. Am f Med 1991; 91: 209-12.

5 Haslock I. Prevalence of NSAID-induced gastrointestinal morbidity and mortality. F Rheumatol 1990; 17 (suppl 20): $2-6$.

6 Hawkey C J. Non-steroidal anti-inflammatory drugs and peptic ulcers. Facts and figures multiply, but do they add up? BMF 1990; 300: 278-84.

7 Griffin M R, Piper J M, Daugherty J R, Snowden M, Ray W A. Nonsteroidal anti-inflammatory drug use and increased risk for peptic ulcer disease in the elderly persons. Ann Intern Med 1991; 114: 257-62.

8 Piper J M, Ray W R, Daugherty J R, Griffin M R. Corticosteroid use and peptic ulcer disease: role of nonsteroidal anti-inflammatory drugs. Ann Intern Med 1991; 114: 735-40.

9 Malone D E, McCormick P A, Daly L, Jones B. Peptic ulcer in rheumatoid arthritis - intrinsic or related to drug in rheumatoid arthritis - intrinsic or re
therapy? $B r \mathcal{~ R h e u m a t o l ~ 1 9 8 6 ; ~ 2 5 : ~ 3 4 2 - 4 . ~}$

10 Arnett F C, Edworthy S M, Bloch D A, et al. The American Rheumatism Association 1987 revised criteria for the classification of rheumatoid arthritis. Arthritis Rheum 1988; 31: 315-24.

11 Rothman K J. Modern epidemiology. 6th ed. Boston, Toronto: Little, Brown: 1986

12 Barrison I. Prophylaxis against non-steroidal induced upper gastrointestinal side effects. Ann Rheum Dis 1991; 50 207-9.

13 Llewellyn J G, Pritchard M H. Influence of age and disease state in non-steroidal anti-inflammatory drug associated state in non-steroidal anti-inflammatory drug
gastric bleeding. $\mathcal{F}$ Rheumatol 1988; 15: 691-4.

14 Mesmer J, Reitman D, Sachs H S, Smith H, Chalmers T C. Association of adrenocorticosteroid therapy and peptic-ulcer disease. N Engl F Med 1983; 309: 21-4

15 Spiro H. Is steroid ulcer a myth? $N$ Engl f Med 1983; 309: 405-7.

16 Guslandi $M$, Tittobello A. Steroid ulcers: a myth revisited. Steroids cause peptic ulcers only when given together with nonsteroidal anti-inflammatory drugs. $B M F$ 1992; 304: 655-6.

17 Selley M L, Bourne D J, Bartlett M R, et al. Occurrence of $(E)$-4-hydroxy-2-nonenal in plasma and synovial fluid of $(E)$-4-hydroxy-2-nonenal in plasma and synovial fluid
of patients with rheumatoid arthritis and osteoarthritis. of patients with rheumatoid arth
Ann Rheum Dis 1992; 51: 481-4.

18 Wallace J L. Lipid mediators of inflammation in gastric ulcer. Am f Physiol 1990; 258: G1-11.

19 Kauffman G L, Aures D, Grossman M I. Intravenous indomethacin and aspirin reduce basal gastric mucosal blood flow in dogs. Am $\mathcal{F}$ Physiol 1980; 238: G131-4.

20 Szabo S. Pharmacologic approaches and pathogenic basis for NSAID gastropathy: prevention and treatment. Pract Gastroenterol 1991; 15: 30-43.

21 Wallace J L, Keenan C M, Granger N. Gastric ulceration induced by non-steroidal anti-inflammatory drugs is a G462-7.

22 Wallace J L, Arfors K I, McKnight G W. A monoclonal antibody against the CD 18 leucocyte adhesion molecule prevents indomethacin-induced gastric damage in the rabbit. Gastroenterology 1991; 100: 878-83. 